\title{
Mathematical modeling of moisture loss, oil uptake and colour kinetics during deep fat frying of onion slices
}

\author{
D. RAMESH BABU
}

\begin{abstract}
Effects of frying temperature, frying time and pre-fry-drying time on kinetics of moisture loss and oil uptake during frying were studied. Colour development during frying were also measured in terms of Hunter L, a, b parameters. Onion slices of $3 \mathrm{~mm}$ thickness were used for frying at 135,150 and $165^{\circ} \mathrm{C}$. The experimental data on moisture loss and oil uptake were fitted to a first order exponential model and kinetic co-efficients for mass transfer were calculated. Kinetic co-efficients were found to increase from $0.595-0.803 \mathrm{~min}^{-1}$ for moisture loss and from $0.38-0.563 \mathrm{~min}^{-1}$ for oil uptake with increase in frying temperature. Temperature dependence of kinetic co-efficients for moisture loss and oil uptake values were described by Arhenious type equation with activation energies of $1.88 \times 10^{3} \mathrm{KJ} / \mathrm{kg}$ mol for moisture loss and $2.3 \times 10^{3} \mathrm{KJ} / \mathrm{kg}$ mol for oil uptake, respectively. As the pre-frydrying time increased from 0 to $60 \mathrm{~min}$, kinetic co-efficients were found to decrease from 0.71 to $0.617 \mathrm{~min}^{-1}$ for moisture loss and 0.442 to $0.326 \mathrm{~min}^{-1}$ for oil uptake. 60 minutes pre-drying reduced the oil content by 22.88 per cent. The mathematical modeling of colour parameters with respect to time and of frying and pre-fry drying time shown best fit with polynomial equation of third order. Two distinct periods (colour development and degradation) of colour changes observed as indicated by Hunter $a$ and $b$ values. During colour development period Hunter a and b values increased with temperature indicating golden surface colour.
\end{abstract}

KEY WORDS : Colour kinetics, Deep fat frying, Mass transfer, Modelling, Onion slices

How to cite this Article : Ramesh Babu, D. (2017). Mathematical modeling of moisture loss, oil uptake and colour kinetics during deep fat frying of onion slices. Engg. \& Tech. in India, 8 (1\&2) : 39-48; DOI : 10.15740/HAS/ETI/8.1\&2/ 39-48. 